\title{
Enantioselective Synthesis of Alkylidenecyclobutanones via Formal Vi- nylidene Insertion into Cyclopropanone Equivalents
}

\author{
Christopher M. Poteat and Vincent N. G. Lindsay* \\ Department of Chemistry, North Carolina State University, 2620 Yarbrough Drive, Raleigh, North Carolina 27695, USA.
}

\begin{abstract}
Sulfonylcyclopropanols are employed here as efficient cyclopropanone equivalents in a formal vinylidene insertion process, providing the first general synthetic route to enantioenriched alkylidenecyclobutanones. The addition of an alkenyl-Grignard reagent to the cyclopropanone leads to an alkenylcyclopropanol capable of electrophilic activation by NBS, triggering a regio- and stereospecific 1,2migration and the formation of a brominated cyclobutanone intermediate prone to elimination. The parent $\beta$-amino ketone can also be accessed by one-pot aza-Michael addition to the resulting product, and activation of the alkenylcyclopropanol intermediate with other electrophiles such as $\mathrm{HCl}$ or $m \mathrm{CPBA}$ led to the controlled formation of a variety of chiral cyclobutanones and $\gamma$-lactones via alternative pathways.
\end{abstract}

The ring expansion or ring-opening of strained cyclic compounds constitutes a key strategy in organic synthesis for the elaboration of complex molecules. ${ }^{1}$ The relevance of cyclobutanone derivatives in this regard cannot be understated, ${ }^{2}$ with countless strain-releasing transformations now available to synthetic chemists, thus allowing rapid access to a range of structurally complex and diverse scaffolds. ${ }^{3}$ More particularly, alkylidenecyclobutanones ${ }^{4,5}$ have been employed as privileged substrates in stereospecific ring-opening or rearrangements ${ }^{4 a-b}$ and constitute divergent substrates leading to functionalized cyclobutanones via conjugate addition of heteronucleophiles $^{4 c, 50-p}$ or organometallic reagents, ${ }^{4 d-e, 5 t}$ conjugate reduction $^{4 \mathrm{f}-\mathrm{h}, 5 \mathrm{c}, \mathrm{q}-\mathrm{r}}$ or hydroformylation reactions. ${ }^{4 \mathrm{i}}$ Moreover, these species have been employed as unique precursors of oxatetramethyleneethane intermediates via photoinduced electron transfer. ${ }^{4 j-1}$ While they can be accessed in racemic form by a variety of approaches including the $[2+2]$ cycloaddition of ketenes with allenes, $^{\text {sa-f }}$ the carbonylation or oxidation of alkylidenecyclopropanes, ${ }^{5 \mathrm{~g}-\mathrm{k}}$ the rearrangement of 1-alkynylcyclopropanols ${ }^{5 \mathrm{l}-\mathrm{n}}$ or by classical condensation or cyclization strategies, ${ }^{50-2}$ the general enantioselective access to alkylidenecyclobutanones still remains elusive. An interesting approach to racemic cyclobutanones reported by Wasserman and co-workers involves the electrophilic activation and ring expansion of 1-vinylcyclopropanol, which in turn can be synthesized by vinyl Grignard addition to hemiketal 1, used as a cyclopropanone surrogate (Scheme 1a).,7 While cyclobutanone derivatives are relatively stable to isolation and storage, cyclopropanones are often highly unstable and prone to multiple decomposition pathways, ${ }^{1 \mathrm{~d}, 8,9}$ and it is thus often more convenient to form them in situ via elimination from a surrogate such as 1 (Scheme 1b) ${ }^{8 d, 10}$ Due in part to the poor leaving group ability of alkoxides, hemiketals 1 require harsh conditions to equilibrate to the cyclopropanone and often lead to low yields of the desired rearranged products, as exemplified here in a racemic cyclobutanone synthesis ( $29 \%$ overall yield, see Scheme 1a). ${ }^{6}$ Recently, our group reported an expedient synthesis of optically active 1-sulfonylcyclopropanols $2,{ }^{11}$ which constitute stable yet highly reactive and modular surrogates of cyclopropanone derivatives. ${ }^{12}$ This approach is in fact the first general enantioselective route to cyclopropanone equivalents, and later allowed us to access enantioenriched 4-substituted $\beta$ lactams using a formal nitrene insertion reaction with simple $N$ substituted hydroxylamines as reagents (Scheme 1c). ${ }^{11}$

Scheme 1. Reactivity of various cyclopropanone equivalents and application in $(3+1)$ ring expansion processes.

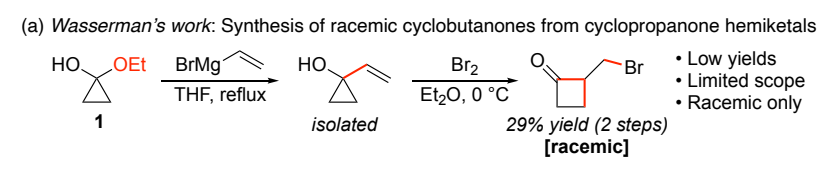

(b) Comparison of hemiketals $\mathbf{1}$ and 1 -sulfonylcyclopropanols $\mathbf{2}$ as cyclopropanone surrogates

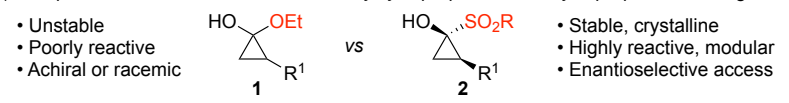
(c) Our previous work: Formal nitrene insertion Cognizant of the superior reactivity of surrogates 2 towards the addition of organometallic reagents to afford chiral tertiary cyclopropanols, ${ }^{12 a}$ we envisioned that they would constitute privileged substrates for the production of optically active cyclobutanones via an analogous stereospecific ring expansion pathway. Herein we report the first general route to enantioenriched alkylidenecyclobutanones via a formal vinylidene insertion process into chiral cyclopropanones starting from readily accessible 1sulfonylcyclopropanols 2 as surrogates (Scheme 1d). The addition of an alkenyl nucleophile to substrates 2 followed by appropriate electrophilic activation with $N$-bromosuccinimide (NBS) was found to trigger a fully regio- and stereospecific 1,2-migration, leading to a bromocyclobutanone prone to elimination. A number of chiral alkylidenecyclobutanones could be obtained through variation of the alkenyl nucleophile and cyclopropanone substituents, and alternative activation of the allylic alcohol with $\mathrm{HCl}$ or $\mathrm{mCPBA}$ 
led to the controlled formation of chiral saturated cyclobutanones and $\gamma$-lactones instead. Other applications of this chemistry documented here include the synthesis of $\beta$-aminocyclobutanones via in situ aza-Michael addition, the use of a $\beta$-bromo alkylidenecyclobutanone as a cross-coupling partner, and the stereospecific formation of $\alpha$-quaternary cyclobutanones. Considering the relevance of chiral cyclobutanones and alkylidenecyclobutanones as strained building blocks in synthesis, ${ }^{2,4}$ this work should find broad applicability in the elaboration of complex and biologically relevant molecules.

Our preliminary studies focused on the addition of vinylmagnesium bromide to substrate $2 \mathrm{a}$ to yield the corresponding 1vinylcyclopropanol, and identified the use of an excess organometallic reagent at $-78^{\circ} \mathrm{C}$ as crucial to the overall reaction efficiency. ${ }^{13}$ We also observed that NBS was a superior electrophile to trigger the subsequent ring expansion, presumably via an hydroxycyclopropylbromonium species, leading to quantitative NMR yields of the ring-expanded bromocyclobutanone from the crude 1vinylcyclopropanol intermediate. This brominated product was found to be highly sensitive to elimination by mild base, ${ }^{14}$ which prompted us to pursue a one-pot sequence to alkylidenecyclobutanones 3. To our delight, optimal conditions for the overall process from $2 \mathrm{a}$ were rapidly identified, involving the sequential stoichiometric addition of NBS and $\mathrm{Et}_{3} \mathrm{~N}$ at room temperature to the crude 1 -vinylcyclopropanol intermediate, affording $3 \mathrm{a}$ in $76 \%$ isolated yield from 1-sulfonylcyclopropanol $\mathbf{2 a}$ with complete regio- and stereospecificity (Scheme 2). Using our previously developed twostep sequence to enantioenriched cyclopropanone equivalents from methyl phenyl sulfone ${ }^{11}$ and in order to explore the scope of accessible alkylidenecyclobutanones, diverse chiral substrates $\mathbf{2 a - 2} \mathbf{g}$ were synthesized and submitted to our formal vinylidene insertion sequence. When employing vinylmagnesium bromide as nucleophile, chiral methylenecyclobutanones $3 a-3 e$ were obtained in moderate to good overall yields and high enantiomeric purity, tolerating either monosubstituted (3a-3c), gem-disubstituted (3d) or 2,3-disubstituted (3e) substrates with similar efficiency. In the case of $3 \mathrm{~d}$, additional time and heat was required for the elimination to proceed, presumably due to increased steric hindrance during deprotonation. The use of commercially available 2-methyl-1propenylmagnesium bromide as nucleophile led to tetrasubstituted olefin $\mathbf{3 f}$ in moderate yield. Employing freshly prepared trans- $\beta$ styrenylmagnesium bromide efficiently gave access to $\beta$-phenyl alkylidenecyclobutanones $\mathbf{3 g}$-3i in various $E: Z$ ratios, where alkene isomerization was found to occur during chromatography. ${ }^{51,13}$ Gratifyingly, all products $\mathbf{3 a - 3 i}$ were obtained as single regioisomers without the need for purification of the vinylcyclopropanol intermediates, and no significant loss of stereochemical information was observed in any case, confirming the stereospecificity of the 1,2migration occurring upon olefin bromination. Interestingly, the alkylidenecyclobutanone initially produced can be directly employed as an electrophile in an aza-Michael reaction in one-pot, leading to the clean formation of a $\beta$-aminoketone such as $\mathbf{4}$ (Scheme 3). Upon heating and addition of a catalytic amount of $\mathrm{Yb}(\mathrm{OTf})_{3}$ as Lewis acid, the succinimide liberated as byproduct during olefin activation can act as a nucleophile in the final step to directly afford a protected $\beta$-amino cyclobutanone 4 with high efficiency. A single trans diastereomer of the cyclobutanone is obtained in the process, likely due to thermodynamic keto-enol equilibration occurring under these conditions. ${ }^{5 \mathrm{q}, 7 \mathrm{f}}$
Scheme 2. Scope of accessible alkylidenecyclobutanones by formal vinylidene insertion into cyclopropanone equivalents $s^{a, b}$

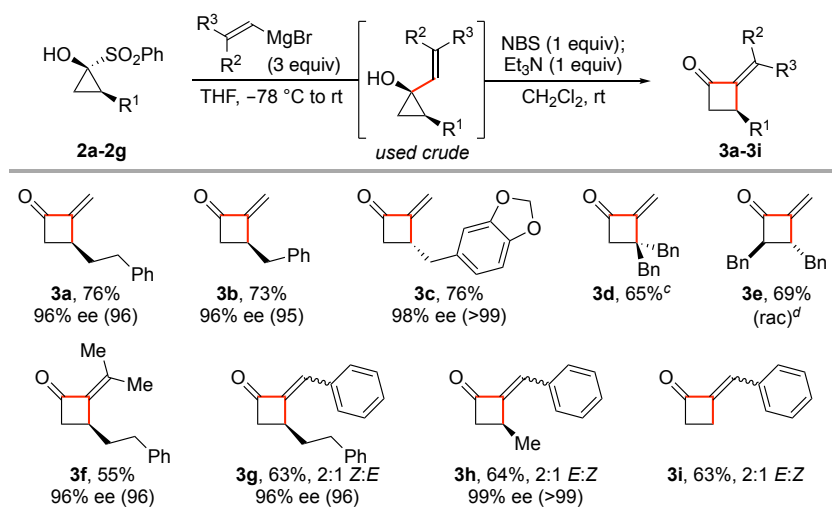

${ }^{a}$ Isolated yields from $\mathbf{2 a - 2 g}$. ${ }^{b}$ Enantiomeric excesses were determined by HPLC analysis using a chiral stationary phase (ee of starting material 2 in parentheses). ${ }^{c}$ Heated to reflux for $18 \mathrm{~h}$ after addition of $\mathrm{Et}_{3} \mathrm{~N}$. ${ }^{d}$ Racemic substrate $2 \mathbf{e}$ was used.

Scheme 3. Direct synthesis of enantioenriched $\beta$-aminoketone 4 by one-pot aza-Michael addition of the succinimide byproduct ${ }^{2, b}$

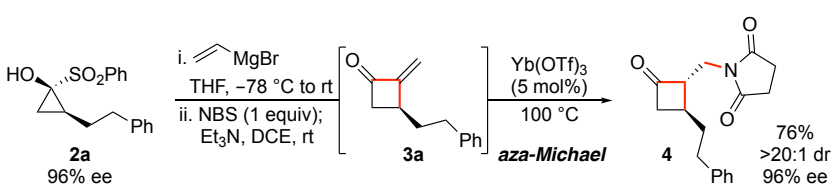

${ }^{a}$ Isolated yield from 2a. ${ }^{b}$ Enantiomeric excess was determined by HPLC analysis using a chiral stationary phase

The addition of a 1-substituted alkenyl-metal reagent such as $\alpha$ styrenylmagnesium bromide as initial nucleophile in this transformation efficiently leads to an enantioenriched $\alpha$-quaternary $\beta$ bromocyclobutanone (e.g. 5), which cannot undergo further elimination to an alkene following olefin activation and 1,2-migration (Scheme 4a). When ethynylmagnesium bromide was employed instead, the 1-alkynylcyclopropanol initially formed underwent an analogous rearrangement upon activation with NBS, directly affording $\beta$-brominated alkylidenecyclobutanone 6 (Scheme $4 \mathrm{~b}$ ). This compound can then be effectively employed as a substrate in a Suzuki cross-coupling reaction to furnish an ester-functionalized alkylidenecyclobutanone 7 . Such a sequence should prove particularly useful as an alternative route to alkylidenecyclobutanones when functional group compatibility is an issue, either during the initial Grignard addition or the electrophilic alkene activation step.

Scheme 4. Synthesis and application of brominated cyclobutanones 5 and 6 via the addition of $a$-styrenylmagnesium bromide (a) or ethynylmagnesium bromide (b) as initial nucleophiles ${ }^{a, b}$

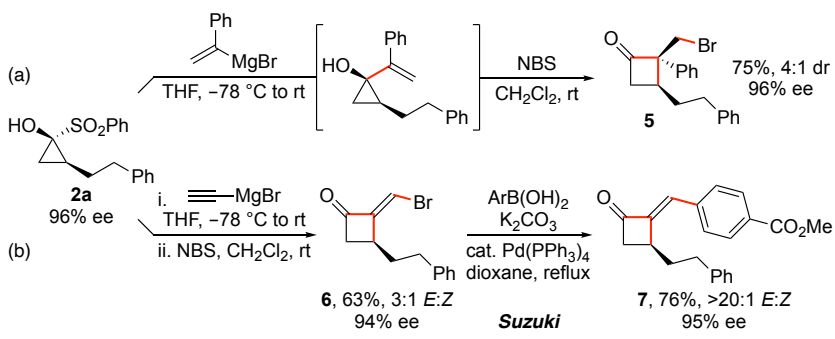

${ }^{a}$ Isolated yields. ${ }^{b}$ Enantiomeric excesses were determined by HPLC analysis using a chiral stationary phase. 
The stereospecific 1,2-migration of the ring expansion sequence can also be triggered by the addition of electrophiles other than NBS to the crude 1-vinylcyclopropanol intermediate, directly leading to the corresponding saturated chiral cyclobutanones in moderate to good overall yields (Scheme 5). ${ }^{6 a, 10 a-b}$ For example, treatment of this intermediate with a few drops of concentrated $\mathrm{HCl}$ in $\mathrm{CH}_{2} \mathrm{Cl}_{2}$ at room temperature led to enantioenriched $\alpha$-methylated cis-cyclobutanone 8 as a single diastereomer, following protonation of the vinyl group and 1,2-migration (Scheme 5a, top). Stoichiometric addition of $m C P B A$ instead led to epoxidation of the allylic alcohol, initiating a stereospecific 1,2-migration and affording cis- $\beta$ hydroxycyclobutanone 9 in good overall yield (Scheme 5a, bottom). During this process, we observed the formation of a small amount of $\gamma$-lactone 10a, presumably arising from Baeyer-Villiger oxidation of product 9 , even when only one equivalent $m C P B A$ was added for the epoxidation step. This result highlights the fact that $\beta$-hydroxycyclobutanone 9 constitutes a particularly reactive ketone in such a strain-releasing esterification, and prompted us to investigate a one-pot double ring expansion sequence in the presence of two equivalents $m$ CPBA, directly affording optically active cis- $\gamma$-lactones $10 \mathrm{a}-10 \mathrm{~b}$ in good overall yields (Scheme $5 \mathrm{~b}) .{ }^{15}$ This diastereoselective formal $[3+1+1]$ sequence should prove highly useful considering the relevance of chiral $\gamma$-lactones as synthetic fragments in the formation of biologically active compounds. ${ }^{16}$

Scheme 5. Alternative activation of the vinylcyclopropanol intermediate with $\mathrm{HCl}$ or $\mathrm{mCPBA}$ (a) and stereospecific synthesis of $\boldsymbol{\gamma}$ lactones via one-pot Baeyer-Villiger oxidation $(b)^{a, b}$

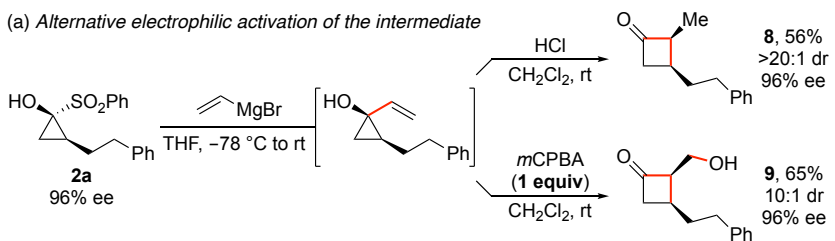

(b) Stereospecific synthesis of $\gamma$-lactones via one-pot Baeyer-Villiger oxidation

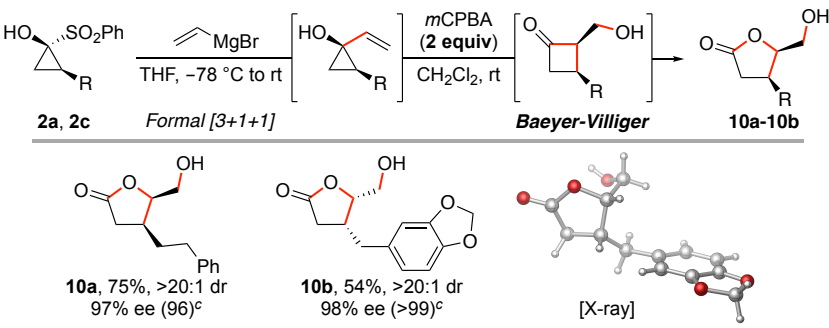

${ }^{a}$ Isolated yields from $2 \mathbf{a}$ or $\mathbf{2 c}$. ${ }^{b}$ Enantiomeric excesses were determined by HPLC analysis using a chiral stationary phase. ${ }^{c}$ ee of starting material $\mathbf{2 a}$ or $\mathbf{2} \mathbf{c}$ in parentheses.

In summary, the first general synthesis of enantioenriched alkylidenecyclobutanones is reported via a formal vinylidene insertion into cyclopropanone derivatives, starting from readily accessible 1sulfonylcyclopropanols as versatile surrogates. ${ }^{11,12}$ The addition of an alkenyl nucleophile followed by electrophilic activation of the resulting crude allylic alcohol with NBS triggers a stereospecific ring expansion occurring in a fully regioselective manner, favoring migration of the most substituted (stereogenic) carbon of the cyclopropyl group. Other activating agents such as $\mathrm{HCl}$ or $m \mathrm{CPBA}$ efficiently led to the formation of chiral saturated ciscyclobutanones instead, which can be further expanded to cis- $\gamma$ lactones in situ by Baeyer-Villiger oxidation in the presence of $m$ CPBA. An alternative divergent route to functionalized alkylidenecyclobutanones is also documented, involving the synthesis of an enantioenriched $\beta$-bromo alkylidenecyclobutanone capable of subsequent Suzuki cross-coupling in good efficiency. Moreover, the one-pot synthesis of a protected $\beta$-aminocyclobutanone is demonstrated via aza-Michael addition, and the stereospecific formation of an $\alpha$-quaternary cyclobutanone is achieved through the use of a 1 -substituted alkenyl-metal reagent as initial nucleophile. Considering the prevalence of chiral cyclobutanones ${ }^{2}$ and alkylidenecyclobutanones ${ }^{4}$ as strained synthetic intermediates and of chiral $\gamma$-lactones in medicinal chemistry, ${ }^{16}$ this work should find general applicability in the elaboration of complex and biologically relevant molecules.

\section{ASSOCIATED CONTENT}

\section{Supporting Information}

Experimental details and spectroscopic data. The Supporting Information is available free of charge on the ACS Publications website. Crystallographic data for compound $\mathbf{1 0 b}$ : $\mathrm{C}_{13} \mathrm{H}_{14} \mathrm{O}_{5}$ (CIF)

\section{AUTHOR INFORMATION}

\section{Corresponding Author}

*Email: vlindsa@ncsu.edu

\section{Author Contributions}

The manuscript was written through contributions of all authors.

ORCID

Christopher M. Poteat: 0000-0003-3859-6252

Vincent N. G. Lindsay: 0000-0002-7126-325X

Notes

The authors declare no competing financial interest.

\section{ACKNOWLEDGMENT}

Dedicated to Prof. André B. Charette on the occasion of his 60th birthday. This work was supported by North Carolina State University startup funds. All X-ray, nuclear magnetic resonance (NMR) spectroscopy, and high-resolution mass spectrometry (HRMS) measurements were performed by the Molecular Education, Technology, and Research Innovation Center (METRIC) at NC State University, which is supported by the State of North Carolina. We are grateful to Dr. Roger D. Sommer for X-ray analysis of $10 \mathbf{b},{ }^{15}$ visualized here using CYLView. ${ }^{17}$ C.M.P. is grateful to NC State University for a Percy Lavon Julian Award in Organic Chemistry.

\section{REFERENCES}

(1) (a) Advances in Strain in Organic Chemistry. Halton, B., Ed.; London, England ; Greenwich, Conn. : JAI Press, c1991-1997.: 1997. (b) Advances in Strained and Interesting Organic Molecules. Halton, B., Ed.; Stamford, Conn.: JAI Press, c1999-: 2020. (c) Wiberg, K. B. Angew. Chem. Int. Ed. 1986, 25, 312-322. (d) Bach, R. D.; Dmitrenko, O. J. Am. Chem. Soc. 2006, 128, 4598-4611. (e) Dudev, T.; Lim, C. J. Am. Chem. Soc. 1998, 120, 4450-4458. (f) Liebman, J. F.; Greenberg, A. Chem. Rev. 1976, 76, 311-365. (g) Liebman, J. F.; Greenberg, A. Chem. Rev. 1989, 89, $1225-1246$.

(2) For selected reviews on the synthesis and applications of cyclobutane and cyclobutanone derivatives, see: (a) Namyslo, J. C.; Kaufmann, D. E. Chem. Rev. 2003, 103, 1485-1538. (b) Lee-Ruff, E.; Mladenova, G. Chem. Rev. 2003, 103, 1449-1484. (c) Salaün, J. Product Class 2: Cyclobutanones and Their Precursors. In Science of Synthesis, Category 4, Compounds with Two Carbon Heteroatom Bonds 1st ed. (Ed.: Cossy, J.), 
Georg Thieme Verlag, Stuttgart, 2005, 26, pp. 557-606. (d) Poplata, S.; Tröster, A.; Zou, Y.-Q.; Bach, T. Chem. Rev. 2016, 116, 9748-9815. (e) Chen, P.-h.; Dong, G. Chem. Eur. J. 2016, 22, 18290-18315. (f) Fumagalli, G.; Stanton, S.; Bower, J. F. Chem. Rev. 2017, 117, 9404-9432. (g) Seiser, T.; Saget, T.; Tran, D. N.; Cramer, N. Angew. Chem. Int. Ed. 2011, 50, 7740-7752. (h) Secci, F.; Frongia, A.; Piras, P. P. Molecules 2013, 18, 15541-15572. (i) Xu, Y.; Conner, M. L.; Brown, M. K. Angew. Chem. Int. Ed. 2015, 54, 11918-11928. (j) Wang, M.; Lu, P. Org. Chem. Front. 2018, 5, 254-259. (k) Sietmann, J.; Wiest, J. M. Angew. Chem. Int. Ed. 2020, 59, 6964-6974. (1) Barday, M.; Bouillac, P.; Coquerel, Y.; Amatore, M.; Constantieux, T.; Rodriguez, J. Eur. J. Org. Chem. 2021, 3023-3034. (m) Wang, M.; Zhong, C.; Lu, P. Synlett 2021, DOI: 10.1055/a-1493-9489. (n) "Cyclobutanone": Lee-Ruff, E. in Encyclopedia of Reagents for Organic Synthesis, 2nd ed. (Eds.: Charette, A. B.; Crich, D.; Fuchs, P. L.), Wiley, Chichester, 2001.

(3) For selected examples of cyclobutanone rearrangements employed in synthesis, see: (a) Frankowski, K. J.; Liu, R.; Milligan, G. L.; Moeller, K. D.; Aubé, J. Angew. Chem. Int. Ed. 2015, 54, 10555-10558. (b) Wendt, J. A.; Gauvreau, P. J.; Bach, R. D. J. Am. Chem. Soc. 1994, 116, 9921-9926. (c) Oh, J. Tetrahedron Lett. 1997, 38, 3249-3250.

(4) For selected applications of alkylidenecyclobutanones, see: (a) Zhou, Y.; Rao, C.; Song, Q. Org. Lett. 2016, 18, 4000-4003. (b) Feng, S.X.; Yang, S.; Tu, F.-H.; Lin, P.-P.; Huang, L.-L.; Wang, H.; Huang, Z.-S.; Li, Q.J. Org. Chem. 2021, 86, 6800-6812. (c) Parr, B. T.; Pastor, R.; Sellers, B. D.; Pei, Z.; Jaipuri, F. A.; Castanedo, G. M.; Gazzard, L.; Kumar, S.; Li, X.; Liu, W.; Mendonca, R.; Pavana, R. K.; Potturi, H.; Shao, C.; Velvadapu, V.; Waldo, J. P.; Wu, G.; Yuen, P.-w.; Zhang, Z.; Zhang, Y.; Harris, S. F.; Oh, A. J.; DiPasquale, A.; Dement, K.; La, H.; Goon, L.; Gustafson, A.; VanderPorten, E. C.; Mautino, M. R.; Liu, Y. ACS Med. Chem. Lett. 2020, 11, 541-549. (d) Conia, J.-M.; Salaün, J. Bull. Soc. Chim. Fr. 1965, $2747-$ 2750. (e) Bhargava, S.; Hou, J.; Parvez, M; Sorensen, T. S. J. Am. Chem. Soc. 2005, 127, 3704-3705. (f) Chen, Y.; Du, J.; Zuo, Z. Chem 2020, 6, 266-279. (g) Yang, Y.; Li, M.; Cao, H.; Zhang, X.; Yu, L. Mol. Catal. 2019, 474, 110450. (h) Xia, J.; Nie, Y.; Yang, G.; Liu, Y.; Gridnev, I. D.; Zhang, W. Chin. J. Chem. 2018, 36, 612-618. (i) Eshon, J.; Foarta, F.; Landis, C. R.; Schomaker, J. M. J. Org. Chem. 2018, 83, 10207-10220. (j) Ikeda, H.; Tanaka, F.; Miyashi, T.; Akiyama, K.; Tero-Kubota, S. Eur. J. Org. Chem. 2004, 1500-1508. (k) Ikeda, H.; Tanaka, F.; Kabuto, C. Tetrahedron Lett. 2005, 46, 2663-2667. (1) Ikeda, H.; Tanaka, F.; Kabuto, C. Tetrahedron Lett. 2005, 46, 3863-3866.

(5) For selected examples of the synthesis of alkylidenecyclobutanones, see: (a) Bertrand, M.; Gil, G.; Junino, A.; Maurin, R. Tetrahedron 1985, 41, 2759-2764. (b) McCaleb, K. L.; Halcomb, R. L. Org. Lett. 2000, 2, 26312634. (c) Erden, I.; Cao, W.; Price, M.; Colton, M. Tetrahedron 2008, 64, 5497-5501. (d) Leiren, M. K.; Törnroos, K. W.; Sydnes, L. K. Tetrahedron 2017, 73, 3153-3159. (e) Hyatt, J. A.; Raynolds, P. W. Org. React. 1994, 45, 159-646. (f) Tidwell, T. T. in Science of Synthesis: Category 3, Compounds with Four and Three Carbon Heteroatom Bonds, Vol. 23, 23.14, 1st. Edition ed., Georg Thieme Verlag, Stuttgart, 2006; 569-678. (g) Kurahashi, T.; de Meijere, A. Angew. Chem. Int. Ed. 2005, 44, 7881-7884. (h) Crandall, J. K.; Paulson, D. R. J. Org. Chem. 1968, 33, 991-998. (i) Yuan, W.; Dong, X.; Wei, Y.; Shi, M. Chem. Eur. J. 2012, 18, 10501-10505. (j) Su, C.; Cao, J.; Huang, X.; Wu, L.; Huang, X. Chem. Eur. J. 2011, 17, 15791585. (k) Sugita, H.; Mizuno, K.; Saito, T.; Isagawa, K.; Otsuji, Y. Tetrahedron Lett. 1992, 33, 2539-2542. (1) Markham, J. P.; Staben, S. T.; Toste, F. D. J. Am. Chem. Soc. 2005, 127, 9708-9709. (m) Trost, B. M.; Xie, J.; Maulide, N. J. Am. Chem. Soc. 2008, 130, 17258-17259. (n) Hashmi, A. S. K.; Wang, T.; Shi, S.; Rudolph, M. J. Org. Chem. 2012, 77, 7761-7767. (o) Aljancic-Solaja, I.; Rey, M.; Dreiding, A. S. Helv. Chim. Acta 1987, 70, 1302-1306. (p) Vidal, J.; Huet, F. J. Org. Chem. 1988, 53, 611-616. (q) Honda, T.; Kimura, N. J. Chem. Soc., Chem. Commun. 1994, 77-78. (r) Hassner, A.; Dillon, J.; Onan, K. D. J. Org. Chem. 1986, 51, 3315-3319. (s) Ishida, M.; Minami, T.; Agawa, T. J. Org. Chem. 1979, 44, 2067-2073. (t) Chang, E. L.; Bolte, B.; Lan, P.; Willis, A. C.; Banwell, M. G. J. Org. Chem.
2016, 81, 2078-2086. (u) Vinson, N. A.; Day, C. S.; Welker, M. E. Organometallics 2000, 19, 4356-4368. (v) Mikami, K.; Kishi, N.; Nakai, T. Tetrahedron Lett. 1983, 24, 795-798. (w) Kishi, N.; Mikami, K.; Nakai, T. Tetrahedron 1991, 47, 8111-8118. (x) Ceylan, M.; Findik, E. Synth. Commun. 2009, 39, 1046-1054. (y) Chen, X.-T.; Bhattacharya, S. K.; Zhou, B.; Gutteridge, C. E.; Pettus, T. R. R.; Danishefsky, S. J. J. Am. Chem. Soc. 1999, 121, 6563-6579. (z) Chen, X.-T.; Gutteridge, C. E.; Bhattacharya, S. K.; Zhou, B.; Pettus, T. R. R.; Hascall, T.; Danishefsky, S. J. Angew. Chem. Int. Ed. 1998, 37, 185-186.

(6) (a) Wasserman, H. H.; Hearn, M. J.; Cochoy, R. E. J. Org. Chem. 1980, 45, 2874-2880. For analogous 1,2-rearrangement of tertiary cyclopropanols leading to cyclobutanone derivatives, see: (b) Cha, J. K.; Cho, S. Y. Org. Lett. 2000, 2, 1337-1339. (c) Cha, J. K.; Youn, J.-H.; Lee, J. Org. Lett. 2001, 3, 2935-2938. (d) Cha, J. K.; Oh, H.-S.; Lee, H. I. Org. Lett. 2002, 4, 3707-3709. (e) Cha, J. K.; Lysenko, I. L.; Oh, H.-S. J. Org. Chem. 2007, 72, 7903-7908. For a recent rearrangement of vinylcyclopropanes leading to alkylidenecyclopropanes instead, see: (f) Hari, D. P.; Madhavachary, R.; Fasano, V.; Haire, J.; Aggarwal, V. K. J. Am. Chem. Soc. 2021, 143, 7462-7470.

(7) Another approach to cyclobutanones via ring-expansion of cyclopropanones also includes the reaction of two equivalents of an unstabilized diazoalkane with a ketene, affording a cyclopropanone intermediate capable of further ring expansion, typically leading to mixtures of regio- and diastereomers: (a) Lipp, P.; Köster, R. Ber. Dtsch. Chem. Ges. B. 1931, 64, 2823-2825. (b) Lipp, P.; Buchkremer, J.; Seeles, H. Ann. Chem. 1932, 499, 1-25. (c) Kaarsemaker, S.; Coops, J. Recl. Trav. Chim. Pays-Bas 1951, 70, 1033-1041. (d) Semenow, D. A.; Cox, E. F.; Roberts, J. D. J. Am. Chem. Soc. 1956, 78, 3221-3223. (e) Turro, N. J.; Gagosian, R. B. J. Chem. Soc. D 1969, 949-950. (f) Turro, N. J.; Gagosian, R. B. J. Am. Chem. Soc. 1970, 92, 2036-2041.

(8) For reviews on the synthesis and applications of cyclopropanone derivatives and their equivalents, see: (a) Turro, N. J. Acc. Chem. Res. 1969, 2, 25-32. (b) Wasserman, H. H.; Clark, G. M.; Turley, P. C. in Stereochemistry I, Vol. 47, Springer Berlin Heidelberg, Berlin, 1974, pp. 73-156. (c) Wasserman, H. H.; Berdahl, D. R.; Lu T. J. in The Chemistry of the Cyclopropyl Group (Ed.: Z. Rappoport), Wiley, Chichester, 1987, pp. 1455-1532. (d) Salaun, J. Chem. Rev. 1983, 83, 619-632. (e) "Cyclopropanone”: De Kimpe, N. in Encyclopedia of Reagents for Organic Synthesis, 2nd ed. (Eds.: Charette, A. B.; Crich, D.; Fuchs, P. L.), Wiley, Chichester, 2001. (f) Salaün, J.; Product Class 3: Cyclopropanones and Their Precursors. In Science of Synthesis, Category 4, Compounds with Two Carbon Heteroatom Bonds 1st ed. (Ed.: Cossy, J.), Georg Thieme Verlag, Stuttgart, 2005, 26, pp. 607-645. (g) Jang, Y.; Machín Rivera, R.; Lindsay, V. N. G. Synthesis 2021, DOI: 10.1055/a-1519-1670.

(9) For the seminal preparation of cyclopropanone solutions by the reaction of diazomethane with ketene at low temperatures followed by distillation, see: (a) Turro, N. J.; Hammond, W. B. J. Am. Chem. Soc. 1966, 88, 3672-3673. (b) Schaafsma, S. E.; Steinberg, H.; de Boer, T. J. Recl. Trav. Chim. Pays-Bas 1966, 85, 1170-1172. (c) van Tilborg, W. J. M.; Steinberg, H.; de Boer, T. J. Synth. Commun. 1973, 3, 189-196.

(10) (a) Wasserman, H. H.; Clagett, D. C. J. Am. Chem. Soc. 1966, 88, 5368-5369. (b) Wasserman, H. H.; Cochoy, R. E.; Baird, M. S. J. Am. Chem. Soc. 1969, 91, 2375-2376. (c) "1-Ethoxycyclopropanol": Salaün, J. in Encyclopedia of Reagents for Organic Synthesis, 2nd ed. (Eds.: Charette, A. B.; Crich, D.; Fuchs, P. L.), Wiley, Chichester, 2009. (d) "1-Ethoxy-1(trimethylsilyloxy)cyclopropane”: Nakamura, E.; Fadel, A. in Encyclopedia of Reagents for Organic Synthesis, 2nd ed. (Eds.: Charette, A. B.; Crich, D.; Fuchs, P. L.), Wiley, Chichester 2009. (e) Salaün, J.; Marguerite, J. Org. Synth. 1985, 63, 147-151.

(11) Poteat, C. M.; Jang, Y.; Jung, M.; Johnson, J. D.; Williams, R. G.; Lindsay, V. N. G. Angew. Chem. Int. Ed. 2020, 59, 18655-18661.

(12) For synthetic applications of 1-sulfonylcyclopropanols 2 as cyclopropanone equivalents, see ref. 11 and: (a) Machín Rivera, R.; Jang, Y.; Poteat, C. M.; Lindsay, V. N. G. Org. Lett. 2020, 22, 6510-6515. (b) Jang, 
Y.; Lindsay, V. N. G. Org. Lett. 2020, 22, 8872-8876. (c) Liu, J.; An, Y.; Jiang, H.-Y.; Chen, Z. Tetrahedron Lett. 2008, 49, 490-494. (d) An, Y.; Liu, J.; Jiang, H.-Y.; Wang, Y.; Chen, Z. Tetrahedron Lett. 2008, 49, 31243128. (e) Liu, J.; An, Y.; Wang, Y.-H.; Jiang, H.-Y.; Zhang, Y.-X.; Chen, Z. Chem. Eur.J. 2008, 14, 9131-9134. (f) Zhang, Y.-X.; Guo, L.; Wang, Y.-H.; Zhu, L.-L.; Chen, Z.-L. Synth. React. Inorg., Met.-Org., Nano-Met. Chem. 2010, 40, 241-245.

(13) See the supporting information for details.

(14) Attempts to isolate this brominated product via standard column chromatography led to $20 \%$ formation of alkylidenecyclobutanone $3 \mathbf{a}$ via elimination.

(15) Deposition Number 2089064 (for 10b) contains the supplementary crystallographic data for this paper. These data are provided free of charge by the joint Cambridge Crystallographic Data Centre and Fachinformationszentrum Karlsruhe Access Structures service www.ccdc.cam.ac.uk/structures
(16) For selected examples of biologically active chiral $\gamma$-lactones: (a) Tatsuta, K.; Hosokawa, S. Chem. Rev. 2005, 105, 4707-4729 (b) Takahata, H.; Uchida, Y.; Momose, T. J. Org. Chem. 1995, 60, 5628-5633. (c) Elford, T. G.; Hall, D. G. in Strategies and Tactics in Organic Synthesis, Vol. 10 (Ed.: Harmata, M.), Academic Press, 2014, pp. 79-112. (d) Wu, Y.C. in Stud. Nat. Prod. Chem., Vol. 33 (Ed.: Atta ur, R.), Elsevier, 2006, pp. 957-1023. (e) Gao, H.; Zou, J.; Li, J.; Zhao, H. in Stud. Nat. Prod. Chem., Vol. 48 (Ed.: Atta ur, R.), Elsevier, 2016, pp. 347-397. (f) Singh, D.; Devi, N.; Kumar, V.; Malakar, C. C.; Mehra, S.; Rattan, S.; Rawal, R. K.; Singh, V. Org. Biomol. Chem. 2016, 14, 8154-8166. (g) Davidson, S. J.; Pilkington, L. I.; Dempsey-Hibbert, N. C.; El-Mohtadi, M.; Tang, S.; Wainwright, T.; Whitehead, K. A.; Barker, D. Molecules 2018, 23, 3057. (h) Moreno, C. J.; Hernández, K.; Charnok, S. J.; Gittings, S.; Bolte, M.; Joglar, J.; Bujons, J.; Parella, T.; Clapés, P. ACS Catal. 2021, 11, 4660-4669.

(17) CYLview, 1.0b; Legault, C. Y., Université de Sherbrooke, 2009 (https://www.cylview.org/). 
TOC GRAPHIC

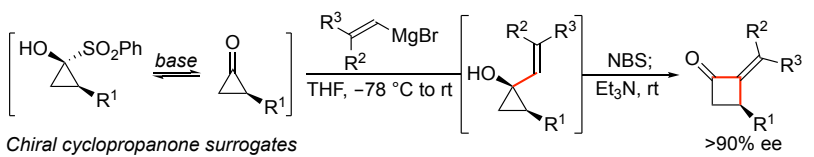

